\section{Procedure}

There were no differences in procedure between Experiment $3 *$ and either Experiment 2 or Experiment 1.

\section{RESULTS AND DISCUSSION}

Again the effect due to pack was not significant $(F<1)$. The remaining analyses disregarded the pack variable. The data for trials to criterion were: "city" $=14.3$; "county" = 15.9; "country" = 15.9; "continent" =12.3. An analysis of variance indicated significant differences among the means $(F=5.80, p<.01)$. The NewmanKeuls test revealed that the city-continent difference was significant at beyond the .05 level, and the county-continent and the country-continent differences were significant at beyond the .01 level. These results based on trials to criterion very nicely replicate the comparable results from Experiment 2.

One indication of a serial structure which has not yet been considered is the degree of symmetry between forward and backward association errors, which can be seen for all three experiments in Fig. 1. The first six points can be thought of as errors which involve forward associations along the serial structure. The last six points indicate backward association errors. For instance, the first error type on the figure involves calling the last item in the serial structure when the first item is correct, e.g., calling "PhD" when "H.S. diploma" is correct. The last error type on the figure is the inverse, e.g., calling "H.S. diploma" when "PhD" is the correct response.

The more symmetrical the error curve, i.e., the more that each of the six forward association error types occupies the same rank as its corresponding backward association error type in terms of difficulty, the more evidence of a serial structure in operation. In order to test the degree of symmetry in each of the three curves, a Spearman Rho was computed for each one. The six forward association errors were ranked from most to least and correlated with the corresponding six backward associations. For Experiment 1 the Rho was .54 , which is not statistically significant $(.83=\mathrm{p}<.05)$. However, for both Experiment 2 and Experiment 3 the Spearman Rho $=.94 ; p<.01$. These data offer strong evidence that a serial structure is affecting the error patterns, at least in Experiments 2 and 3.

Experiments 2 and 3 can be thought of as different conditions within a single experimental design. The independent variable is the presence of either "state" or "continent" as a response item. In comparing the two conditions, e.g., Experiments 2 and 3 , it can be seen that the major difference involves the county-state and state-county error types in Experiment 2 relative to the corresponding county-country and countrycounty error types in Experiment 3 . The rate of errors sharply increases when "state" is taken out of the serial structure. Thus it is likely that the uniqueness of that item. facilitated its learning, whereas its position in the serial structure represented a difficulty. Thus the two effects summed to create an item of moderate difficulty in Experiment 2. The rest of the curves for the two experiments are remarkably similar, which suggests that the serial structure does provide a stable influence on the error patterns. The fact that identical error types, county-country and country-county, occupy very different positions on the error curves of Experiments 2 and 3 testifies to the influence of the serial structure on error patterns.
The three experiments reported here extend the generality of the phenomena first reported by DeSoto \& Bosley (1962), and also provide supportive evidence for the general theory of serial learning recently proposed by Harcum (1967), which emphasizes the learning strategies and the cognitive structures which $S$ brings to the experimental task.

\section{REFERENCES}

DeSOTO, C. B., \& BOSLEY, J. J. The cognitive structure of a social structure. Joumal Abnormal \& Social Psychology, 1962, 64, 303-307.

HARCUM, R. R. Parallel functions of serial learning and tachistoscopic pattem perception. Psychological Review, 1967, 74, 51-62.

POLLIO, H. R, \& DRAPER, D. O. The effect of a serial structure on paired-associate learning. Journal of Verbal Learning \& Verbal Behavior $1966,5,301-308$.

\title{
Rhyme as a determinant of clustering'
}

\section{WESTON A. BOUSFIELD and DAVID $A$. WICKLUND, University of Connecticut, Storrs, Conn. 06268}

This study dealt with rhyme as a determinant of clustering in free recall. The stimuli comprised 12 rhyming pairs of words. The results from $30 \mathrm{Ss}$ showed significant clustering as well as high variance attributable to both Ss and word pairs.

This study explores the efficacy of rhyme as a determinant of clustering. Words may be said to rhyme when their terminal sounds are similar. The phonetic similarity of given words has apparently not been considered in studies of clustering. A possihle reason for this is that Es have generally relied on conventional free-associational or on category norms for the selection of stimulus items. The latter may be described as being of the restricted associational type. Alternatively stated, these norms have served for the selection of groups of directly or mediationally associated words. In these terms, taxonomic categories may be regarded as mediators with special properties of effectiveness for determining the sequential emission of their subordinate items in free recall. The associational interpretation has shown appreciable predictive power in spite of what now appears to be its relatively narrow range of application. The compilers and users of associational norms have tended to regard clang or rhyming associations as being somehow aberrant or immature in nature. Thus Nobel(1952), in his Hullian analysis of meaningfulness as measured by continued associations, regarded clang responses as unacceptable. Flavel et al (1958) classed clang associations as immature. The fact that clang responses appear in free-associational forms for children but not for adults (Palermo \& Jenkins, 1964) gives further apparent support for the assumption of their immaturity. This somewhat evaluative attitude has probably contributed to their neglect and the favoring of what may loosely be termed logically relevant associative responses. It is becoming increasingly evident, however, that other types of responses and characteristics of words have significant roles in verbal learning. For example, acoustic attributes of words are important for short-term memory (Adams, 1967) and imagery can no longer be neglected (Paivio et al, 1966). Rhyme may be classed as an acoustic attribute, and the present study was pianied to determine its effects on clustering with admitted ignorance regarding factors determining its salience. An exploratory study in whis 1 Ss were presented a list comprised of five sets of four rhyming words showed that Ss did indeed recall the words in clusters of rhymed words. The dimension of rhyming, however, was completely confounded with formal similarity (i.e., fat, mat, rat, sat). The present study is designed to minimize such factors. 


\section{METHOD}

Thirty undergraduate Ss provided the basic data. An additional five were added for one of the supplementary analyses. After the completion of the experiment, a new group of $77 \mathrm{Ss}$ gave standard free-associational responses to the 24 stimulus words. These comprised 12 rhyming pairs selected with the plan of avoiding, insofar as possible, duplications of initial and final letters. The words are given here along with their Thorndike-Lorge (1944) G-frequency counts: pie(A)-cry(AA); her(AA)-were(AA); fire(AA)-liar(8); one(AA)-fun(A); key(A)-tea(A); eight(AA)-gate(AA); was(AA)-buzz(16); fox(25)-socks(12); claim(AA)-name(AA); coal(AA)-hole(AA); tough(A)-fluff(2); size(AA)-wise(AA). The last pair constitutes the only exception to the rule of avoiding duplication of terminal letters. The subsequently obtained free-associational norms showed no interitem associations between members of pairs.

A group method of presenting the items involved E's reading them at a 3-sec rate with each of three presentations immediately followed by a 90 -sec period for written free recall. The first presentation had two phases. Initially, the items were both spelled and pronounced. The second phase, with a different randomized order, immediately followed and involved pronouncing the items only. Each of the three recalls was written on a separate page of a booklet. Finally, Ss were asked to report whether they could make any observations on how the word list had been compiled.

\section{RESULTS}

The means of the items recalled for three successive trials were: 14.57, 17.57, and 19.50. A trend analysis indicated the trials effect was significant $[F(2,58)=53.79$, $\mathrm{p}<.001]$. The clustering effect was assessed according to the method of Bousfield \& Bousfield (1966). If all the items were clustered in recall, the obtained stimulus category repetition, O(SCR), would have a value of 12.00 . According to their Formula II, the computed expected value, E(SCR), would be 1.00 . For the present study, the three successive $O(S C R)$ values were $1.33,1.67$, and 2.60 . The corresponding $\mathrm{E}(\mathrm{SCR})$ values were 0.60 , 0.72 , and .834 . The obtained values, O(SCR), were obviously small, but $t$ tests of the three respective differences between the obtained and the expected values, the $0-E(S C R)$, were significant at the following levels: $\mathrm{p}<.01, \mathrm{p}<.02$, and $\mathrm{p}<.02$. A trend analysis indicated the trials effect for the $0-E(S C R)$ was significant $[\mathrm{F}(2,58)=4.62, \mathrm{p}<.025]$.

A striking characteristic of the data was the high variation in the proneness of the rhyming pairs to cluster. This was revealed in an analysis of the third recall with the addition of 5 randomly selected Ss bringing the $\mathrm{N}$ up to 35 . The total clusters of the pairs were as follows: pie-cry, 1; was-buzz, 4; coal-hole, 5; fire-liar, 5; key-tea, 5; fox-socks, 6; size-wise, 6; her-were, 8 ; one-fun, 10; tough-fluff, 10; eight-gate, 13; claim-name, 22. The mean number of clusters per pair is 7.92. Several attempts were made to discover possible determinants of the proneness of the pairs to cluster. The high variance attributable to both the pairs and Ss contributed to the lack of success of this undertaking. One analysis involved translating each word into the In ternational Phonetic Alphabet. The final phonemes in the case of each rhyming pair are necessarily identical. Three pairs (pie-cry, her-were, and key-tea) have single common terminal phonemes. Of the remaining pairs, all have two, except for fox-socks which has three such elements.

In order to obtain additional information, a 24 by 24 stimulus word matrix was compiled for the third recall from the $35 \mathrm{Ss}$. This matrix showed the number of times each word was followed by every other word in the 35 recalls. A total of 27 such pairs had counts of 4 or more. These were examined for identifiable characteristics including linkages indicated by the free-associational norms. The matrix indicated that the sequences, name-claim and was-were, occurred 15 times each. The count for claim-name was 7 . The high count sequences included 11 of the 12 rhyming pairs. Eleven were presumably linked by natural language mediators (Adams, 1967), six began with common letters, and one had double, but dissimilar, terminal consonants. There were only four associatively related pairs which are given here with their cultural frequencies from the norms: were-was, 11 ; was-were, 9; fox-hole, 5; hole-fox, 1 . It should be noted that several of the pairs had multiple cues assumed to provide a basis for the linking of their components.

No evidence was found for a relationship between the recall frequencies of the individual items and their Thorndike-Lorge (1944) counts. The final analysis was based on the introspective reports and the recall protocols of the $30 \mathrm{Ss}$ of the main group. Eight noted that the entire list comprised rhyming pairs, 13 said some of the words rhymed, and 7 made no comment on rhyme. There were no significant differences in item recall between the three groups. The three respective means for obtained clusters, $\mathrm{O}(\mathrm{SCR})$, were $5.13,1.62$, and 2.14. For the expected clusters, E(SCR), the means were, respectively, $0.98,0.77$, and 0.85 . The only significant difference for the mean O-E(SCR) values was for the results of Ss who noted the entire list comprised rhyming pairs vs the combined results for the remaining two groups $(p<.05)$. Thus, the "insightful" Ss tended to show greater clustering but not more item recall.

\section{DISCUSSION}

This study indicates that rhyme can provide an effective mediational cue for inducing clustering. While recognizing the potency of direct and indirect verbal associations (e.g., Wicklund et al, 1965) as bases for the ordering effect, the present findings add to cumulating evidence that the sequential ordering of words has multiple determinants. These determinants, moreover, vary in their effectiveness. Various types of nonword mediators merit further consideration. Examples of these are letters of the alphabet (Tulving, 1962), and imagery (Paivio et al, 1966). The present study indicates that rhyme should be added to the list of these cues. An obviously needed next step is that of effectively isolating the attributes that determine the potency of the rhyming effect. A possible first step may be that of obtaining norms on the basis of asking Ss to respond to each member of a given set of words with a rhyming associate. The basic need, however, is for the development of theory which will take into account a multiplicity of types of mediational cues which serve as a basis for item retrieval and for sequential ordering in free recall.

\section{REFERENCES}

ADAMS, J. A. Human memory. New York: MoGraw-Hill, 1967.

BOUSFIELD, A. K., \& BOUSFIELD, W. A. Measurement of clustering and of sequential constancies in repeated free recall. Psychological Reports, 1966, 19, 935-942.

FLAVELL, J. H., DRAGUNS, J., FEINBERG, L. D., \& BUDIN, W. A. A microgenetic approach to word association. Journal of Abnormal \& Social Psychology, 1958, 57, 1-7.

NOBLE, C. E. An analysis of meaning. Psychological Review, 1952, 59, 421-430.

PAIVIO, A., YUILLE, J. C., \& SMYTHE, P. C. Stimulus and response abstractness, imagery and meaningfuiness, and reported mediators in paired-associate learning. Canadian Joumal of Psychology, 1966, 20, 362-377.

PALERMO, D. S., \& JENKINS, J. J. Word association norms: Grade school through college. Minneapolis: University of Minnesota Press, 1964.

THORNDIKE, E. L., \& LORGE, I. The teacher's word book of 30,000 words. New York: Columbia University Press, 1944.

TULVING, E. The effect of alphabetical subjective organization on memorizing unrelated words. Canadian Journal of Psychology, 1962, 16, 185-191.

WICKLUND, D. A., PALERMO, D. S., \& JENKINS, J. J. Associative clustering in the recall of children as a function of verbal association strength. Journal of Experimental Child Psychology, 1965, 2, 58-66.

$$
\text { NOTE }
$$

1. Appreciation is extended to Roland $L$. Lizotte and Michael Dorman for assistance in computation of the data. 